\title{
Öğretim Teknolojisi Algısındaki Değişim Durumunun İncelenmesi: Metaforik Bir Çalışma ${ }^{1}$
}

\section{Exploring the Change of Perception on Instructional Technology: A Metaphorical Study}

Salih BiRişÇi ${ }^{\circledR}$, Dr. Öğr. Üyesi, Bursa Uludağ Üniversitesi, Eğitim Fakültesi, salihbirisci@uludag.edu.tr

Birişçi, S. (2021). Öğretim Teknolojisi Algısındaki Değişim Durumunun İncelenmesi: Metaforik Bir Çalışma. Batı Anadolu Eğitim Bilimleri Dergisi, 12 (2), 769-785.

Öz. Bu çalışmada, üniversite öğrenimine yeni başlayan öğretmen adaylarının "öğretim teknolojisi” hakkındaki metaforik algılarının irdelenmesi amaçlanmıştır. Bu amaçla "Öğretim Teknolojilerinin Temelleri" adlı dersin başlangıç ve bitiş aşamalarında öğretim teknolojisi kavramına ilişkin metaforların tespiti ve bunlar arasındaki değişim durumunun belirlenmesi araştırmanın problemini oluşturmaktadır. 2018-2019 güz dönemi içerisinde bir devlet üniversitesinin Bilgisayar ve Öğretim Teknolojileri Eğitimi Bölümü’nde öğrenim gören 24 öğretmen adayının katııımı olarak yer aldığı bu araştırma nitel araştırma yöntemlerinden olgubilim (fenomenoloji) deseni çerçevesince yürütülmüştür. Veri toplama aracı olarak üzerinde "Öğretim teknolojileri ........ gibidir, çünkü ........" ifadesinin yer aldığı yarı yapılandırılmış formlar kullanıımış ve öğrencilerin form üzerinde belirtmiş olduğu ifadeler araştırmanın temel veri kaynağını oluşturmuştur. Elde edilen verilerin çözümlenmesinde içerik analizi yönteminden faydalanılmış olup, ders öncesi 20 (5 kategori) ve ders sonrası aşamada 18 (4 kategori) metafor yapısı kategorilendirilmiştir. Ulaşılan bulgular ışı̆̆ında, gerek ders öncesi gerekse ders sonrası öğretim teknolojisi kavramına ilişkin metaforikyapıların benzerlik gösterdiği ortaya çıkarılmışırı. Buna karşın, öğretimi destekleyici rolünü betimleyen algıların ders sonrası aşama lehine ağırlık kazanmış olması dikkat çekicidir.

Anahtar Kelimeler: Öğretim teknolojisi, Metafor, Öğretmen adayı.

\begin{abstract}
In this study, it is aimed to examine the metaphorical perceptions of pre-service freshman teachers about instructional technology. Determining the metaphors about the perception of instructional technology at the pre-post stages of the course called "Fundementals of Instructional Technologies" and the changing status between them constitutes the problem statement of the study. A phenomenon (phenomenology) pattern, one of the qualitative research methods was used throughout the study. During the 2018-2019 fall semester 24 pre-service teachers studying at the Computer Education and Instructional Technologies department constitute the sample of the research. Semi-structured forms as "Instructional technologies.......because......." were distributed as data collection tool. The results were presented by classifying 20 (5 categories) and 18 (4 categories) metaphors as pre-post course stage. The metaphorical structures regarding the concept of instructional technology are similar for both pre-post stages. On the other hand, it is remarkable that the perceptions describing the role of supporting teaching gained weight in favor of the post-course stage.
\end{abstract}

Keywords: Instructional technology, Metaphor, Pre-service teacher.

\footnotetext{
${ }^{1}$ Bu çalışma, 30 Ekim - 1 Kasım 2019 tarihleri arasında düzenlenen 7. Uluslararası Öğretim Teknolojileri ve Öğretmen Eğitimi Sempozyumu'nda sözlü sunulan bildirinin genişletilmiş ve geliştirilmiş halidir.
} 


\section{Extended Abstract}

Introduction. It is emphasized that the patterns of perception that may occur by individuals can be explained through metaphorical structures. According to Lakoff and Johnson (2007), metaphor is defined as understanding and experiencing a case according to another phenomenon.Considering the importance of instructional technologies, it is an expected situation that teachers should take advantage of these technologies within the scope of lecturing activities. In this situation it is important to uncover the understanding of instructional technology about why and how it can be implemented during a lesson process. This situation is valid in different departments of educational sciences, and it is seen that it is handled in revealing the level of knowledge of the case, which is especially addressed at the point of teaching. By determining the perceptions to be revealed by teacher candidates, it will be possible to say how they understand this concept, how they can approach this issue in educational activities, how they reflect on the classroom environment and how they will affect their learning and teaching situations. On the other hand, when the nature of the metaphor studies presented in the literature is examined, it is possible to encounter studies that compare metaphoric perception by different groups as well as being reflective of the current situation. However, there is no study that investigate the situation of change in the perception discussed. When evaluated from this point of view, this research is thought to give a different perspective to the studies to be conducted in the field of metaphoric beliefs. In this study, it is aimed to determine and compare the metaphorical perceptions of instructional technology. The comparison consists of pre and post stages of the "Fundamentals of Instructional Technology" course taught in the first year within the scope of the CEIT curriculum which was put into practice in the education faculties in the 2018-2019 academic term.

Method. In this study, a phenomenology pattern was used as qualitative research method in order to determine the perceptions about the concept of instructional technology. The study group of the study consists of 24 pre-service freshman teachers in the Department of Computer Education and Instructional Technologies (CEIT). As the data collection tool that prepared by the researcher was used to determine the perceptions of instructional technology. In this form, the expression "Instructional technologies are like ........ because ........" is used to determine the perceptions of the candidates, and the expressions they express in the empty sections on this form constitute the data source of the research. Content analysis method was used to analyze the metaphoric data obtained. During the analysis process four stages were followed as naming, scanning, compilation and validityreliability (Saban, 2008).The metaphors were categorized under their frequency and percentage values.This study was carried out within the scope of Fundamentalsof Instructional Technologies course taught by the author and took part in the data collection process.

Results. 19 metaphors were formed under the pre-course phase and they were classified into 5 categories. These categories are named as supportive structure, renewal process, need, capacity and immersion. When the structural features are examined, 12 pre-service teachers (60\%) perceive instructional technologies as a supportive structure. 12 metaphors were produced under this category and these were specified as kitchen appliances, channel, rule, space, parent, color, ocean, book, library, building foundation, piggy bank, map, construction. Another category of metaphors specified for instructional technology in the phase of pre-course was determined as the renewal process. It is seen that 3 metaphors put under this category are produced by $4(20 \%)$ teacher candidates. These metaphors are in the form of human, universe and life. On the other hand, the concept of instructional technology was determined by $2(10 \%)$ teacher candidates as a symbol of need. Under this category, it has been determined that 2 metaphors are produced as a requirement and they are in the form of books and colors. As for the post-course phase 18 metaphors about the concept of teaching technology have been created and these are classified into 4 categories. These categories are determined as a supportive structure, renewal process, need and personal development. The most striking among the metaphoric categories formed in the post-course phaseis 
the perception of instructional technologies as a supportive structure. Under this category, 13 metaphors were created by 13 (72\%) teacher candidates, and they are in the form of actor, arrow, communication, stonemason, planet, guide, human brain, light, doctor, color, communication, makeup, piggy bank.

Discussion and Conclusion. As a result of this research carried out in order to reveal the changing status of the metaphorical perceptions related to instructional technology, it is possible to reach the following conclusions: (1) It was revealed that the metaphoric perceptions of the concept of instructional technology before and after the "Basics of Instructional Technologies" course were seen similar. Considering that the participants within the scope of the research are composed of students who have just started higher education, it shows that the effort to include technological developments by the Ministry of National Education creates awareness among them. (2) When the metaphoric structures revealed are examined, it is noteworthy that they were created for students as well as being addressed to teachers during their education. This shows that the perception of teaching technology has been formed by all stakeholders in the education-training process. (3) It is seen that the perceptions that describe the supporting role of instructional technologies have gained weight in favor of the stage after the trainings given in the related course process. (4) Based on the metaphorical structures put forward, it is possible to say that prospective teachers will be conscious about using these technologies during their in-service training. (5) The research conducted is thought to be important in revealing the perceptions of information technology prospective teachers on the concept of instructional technology. In order to see the situation in the perception of instructional technology and to shape this appropriate teaching, it may be suggested to repeat the research with the pre-service teachers who study in different departments and programs. 


\section{Giriş}

İçinde bulunduğumuz 21. yüzyılda teknoloji alanında yaşanan gelişmeler ve bunların yansımalarını savunma, sağlık, ulaşım türündeki disiplinler altında görmek mümkündür. Eğitim, bu disiplinler arasında yer almakla birlikle, Bilgi ve iletişim Teknolojilerinin (BiT) sunmuş olduğu olanakların öğrenme ve öğretme faaliyetleri kapsamında birçok değişimin yaşanmasına sebep olmuş ve olmaya devam etmektedir (Harris, Al-Batainehve Al-Bataineh, 2016). Eğitim faaliyetleri kapsamında teknolojiden faydalanılmasına ilişkin gelişmeler, öğretmen ve öğrenci kapsamındaki tüm paydaşları etkiler hale gelmiştir. Nitekim, meydana gelen Biт olanaklarının geleneksel öğrenme ortamlarına entegre edilmesiyle, etkileşimli öğrenme faaliyetlerine yer verilmesi mümkün olmaktadır (Durak ve Sarıtepeci, 2017; Farisi, 2016). Bu durum, öğrenme-öğretme faaliyetleri ile bilginin yayılması sürecindeki değişimi kaçınılmaz kılmakta olup (Haşlaman, Mumcu ve Usluel, 2007), teknoloji ile eğitim alanlarının bütünleştirilmesi gerekliliğini ön plana çıkarmıştır. Eğitimde teknoloji entegrasyonu şeklinde açıklanan bu durum, teknolojinin öğrenme ve öğretme sürecine dahil edilmesiyle birlikte gerçekleşmektedir (Kaya ve Usluel, 2011).

Eğitimde teknoloji entegrasyonu sürecinde vurgulanmak istenen teknolojik araçların kullanımından ziyade, söz konusu teknolojilerin öğretim programları, öğretmenler ve öğrencilerce gerçekleştirilecek öğretme-öğrenme faaliyetleri üzerine kurgulanması gerektiğidir (Ertmer, 2005; Hew ve Bruch, 2007; Hsu ve Kuan, 2013; Kabakçı Yurdakul, 2011; Mazman ve Usluel, 2011; Perkmen ve Tezci, 2011; Reigeluth ve Joseph, 2002; Wang ve Woo, 2007). Bu noktada, eğitim teknolojisi ile öğretim teknolojisi kavramlarından söz edilmesi gerekliliği yanlış olmamakla birlikte bunlara ait açıklamalarda farklı tanımsal ifadelere yer verildiği görülmektedir. Alanın öncü kuruluşlarından Eğitsel iletişim ve Teknoloji Derneği (Association for Educational Communications and Technology-AECT) eğitim teknolojisi ile ilgili tanımında "uygun teknolojik süreç ve kaynakların yaratılması, kullanılması ve yönetilmesiyle öğrenmeyi kolaylaştırmaya ve performansı artırmaya yönelik çalışma ve etik uygulamalar" şeklindeki ifadelere yer vermektedir. Öğretim teknolojisi ise "öğrenme süreci ve bu süreçte yer verilecek kaynakların tasarımı, geliştirilmesi, kullanılması, yönetilmesi ve değerlendirilmesi aşamalarında yer verilen kuram ve uygulamalar" olarak tanımlanmaktadır (AETC, 2008). Eğitim ve öğretim teknolojisi kavramlarınaher ne kadar aynı anlamda kullanılmaya yatkın olunsa da, tanımsal yapılarından kaynaklı bir takım farklılaşmalar görülmektedir (Gedik, 2017; Toşuntaş, Emirtekin ve Süral, 2019). Bu açıdan değerlendirildiğinde, öğretim teknolojisi ilk süreçte görsel-işitsel araçlar şeklinde sınıflandırılmasının ardından yerini, eğitim-öğretim sürecinde sistematik bir yapılanmaya doğru şekillendirdiğinin söylenmesimümkündür (AECT, 2008; Alkan, 2011; Reiser, 2012). Öğretim teknolojileri adına oluşan bu yapılanmanın ana düşüncesini, sistematik bir süreç dahilinde öğrenme-öğretimi etkili ve verimli kılma noktasında işe koşulması gereken araç-gereçler olarak açıklamak mümkündür (Odabaşı, 2007). Bu bağlamda dersleri sürecinde öğretim teknolojilerinden yararlanacak olan paydaşların, ilgili teknolojilerin gelişim süreçlerini takip ederek uygun koşullar altında faydalanmaları önemli bir unsur olarak görülmektedir.

Eğitim-öğretim sürecinin yürütülmesinde öğretmenlere ait sorumlulukların varlığı yadsınamaz bir gerçek olup, bunlardan birini öğretim faaliyetleri şeklinde göstermek mümkündür (Alpaydın, Kocabaş, Dervişoğulları ve Çakır, 2019; Karataş, 2020). Öğretim ortamlarında yer verilmesi gereken bu faaliyetler etkinlikleri belirleme, tasarlama, geliştirilme ve bunlardan konu anlatımları çerçevesinde faydalanılması şeklinde sınıflandırılabilir (Can, 2019; Demirel, 2004; Erden, 2005; Sezgin, Erdoğan ve Erdoğan, 2017; Şahin İzmirli ve Köse, 2018). Öğretim teknolojilerinin ders anlatımları sürecindeki önemi göz önünde bulundurulacak olursa, öğretmenlerin söz konusu faaliyetler kapsamında öğretim teknolojilerden yararlanmaları gerekliliği beklenen bir durum olarak karşımıza çıkmaktadır. Nitekim öğretim teknolojilerinden faydalanarak gerçekleştirilen öğretimlerin, öğrenmeler üzerindeki olumlu sonuçlarını ortaya koyan pek çok çalışmayla karşılaşılması mümkündür (Gülek ve Demirtaş, 2005; Kıyıcı ve Yumuşak, 2005; Lei ve Zhao, 2008; Özdemir, 2015). Söz konusu 
durum hizmet öncesi süreçte yer alan öğretmen adaylarına ait roller bazında değerlendirilecek olursa, öğretim teknolojilerinden faydalanmayı ve bunları öğretim süreçlerinde yer vermeleri gerekliliğini içselleştirmeleri beklenen bir durum olarak ön görülmektedir. Bu açıdan değerlendirildiğinde, öğretim teknolojilerine yönelik öğretmen adaylarınca sahip olunan algı düzeyinin hizmet öncesi eğitim sürecinde nasıl şekillendiği, sorgulanması gereken durumlardan biri olduğu düşünülmektedir.

Bireylerce oluşabilecek algı örüntülerinin metaforik yapılar yoluyla açıklanabileceği çeşitli araştırmalar dahilinde belirtilmektedir(Mouraz, Pereira ve Monteiro, 2013, s. 100). Lakoff ve Johnson $(2007$, s. 5)'a göre metafor, bir olguyu başka bir olguya göre anlamak ve tecrübe etmek olarak tanımlanmaktadır. Bir başka tanıma göre metafor, soyut veya karmaşık düzeyde bir olgunun anlaşılması ve açıklanması sürecinde faydalanabilecek zihinsel bir araç olarak ifade edilmektedir (Haggis, 2004, s. 182). Eğitim, felsefe, edebiyat, coğrafya gibi birçok bilim dalına ait araştırmalarda kullanımına sıklıkla rastlanan metaforların, öğrenme sürecinde güçlük çekilen soyut kavramların öğrenilmesinde kolaylaştırıcılığı ve kalıcılığı sağlama noktasında işlevleri olduğunu vurgulanmaktadır (Jensen, 2006; Yob, 2003). Yapılan tanımsal ifadelerden hareketle, bireylerce herhangi bir kavramın anlaşılma durumunu ortaya çıkarma adına metaforik yapılara başvurulabileceği mümkün gözükmektedir. Bu açıdan değerlendirildiğinde, öğretmen adaylarınca öğretim teknolojisi olgusu hakkında zihinlerinde oluşan anlamların ortaya çıkarılmasında metaforik algı yapılarına başvurma gerekliği duyulmuştur. Öğretmen adaylarınca yüklenilen anlamlar ve bu manada oluşturulan metaforların ortaya konulması, öğretim teknolojisi kavramının anlaşıımasında yol gösterici olacağı düşünülmektedir.

Bireylerin herhangi bir kavrama dair algılarını metaforlar aracılı̆ıyla ortaya koyan pek çok araştırmayla karşılaşmak mümkündür. Bu durum eğitim bilimlerine ait farklı anabilim dalları içinde geçerli olup, özellikle öğretimi noktasında ele alınan olguya ait bilgi düzeyinin ortaya çıkarılmasında ele alındığı görülmektedir. Bunlar arasında teknoloji, eğitim teknolojisi ve uzaktan eğitim algısını ortaya koyan çalışmaların literatürde kayda değer yer edindiği görülmektedir (Bilgiç, 2021; Çivril, Aruğaslan, ve Özkara Özaydın, 2018; Çoklar ve Bağcı, 2009; Durukan, Hacıoğlu ve Dönmez Usta, 2016; Fidan, 2014;Koç, 2013; Korkmaz ve Ünsal, 2016; Kuru ve Kuru, 2019; Mason, 2018; Özer ve Türel, 2015; Şahin ve Baturay, 2013, Yılmaz ve Güven, 2015). Öğretme ve öğrenme ortamlarında yer verilmesinde taşımış olduğu önem göz önünde bulundurulduğunda, öğretim teknolojisi kavramı ile ilgili hizmet öncesi eğitimde yer alan öğretmen adaylarının zihinlerinde oluşturdukları anlamların ortaya çıkarılması bu çalışmayı önemli kılmaktadır. Adaylarca ortaya konacak algıların belirlenmesiyle, eğitim-öğretim faaliyetlerinde bu konuya nasıl bir yaklaşım içinde bulunacakları, sınıf ortamına nasıl yansıtacakları ve öğrenme-öğretme durumlarına nasıl etkide bulunacağına dair fikir sağlanabileceğini söylemek mümkün olabilecektir. Ancak, söz konusu kavramla ilgili sahip olunan metaforik inanışlar ortaya çıkarılabileceği gibi ele alınan algıdaki değişim durumunun irdelendiği araştırmaya rastlanılmamıştır. Bu açıdan değerlendirildiğinde yapılan bu araştırmanın, metaforik inanışlar alanında yapılacak çalışmalara farkıı bakış açısı kazandıracağı düşünülmektedir. Bu çalışmayla birlikte Bilgisayar ve Öğretim Teknolojileri Eğitimi (BÖTE) bölümünde öğrenim görmeye başlamışbirinci sınıf öğretmen adaylarının "öğretim teknolojisi" algısına yönelik metafor algılarının üniversite eğitimine başlangıç ve süreç içerisinde alınan dersler neticesinde belirlenmesi vebunlar arasındaki değişim durumunun ortayakonulması araştırmanın problemini oluşturmaktadır.

Bilindiği üzere 2018-2019 eğitim-öğretim yılı itibariyle,öğretmenlik mesleği yeterlikleri göz önünde bulundurularak Yükseköğretim Kurulu kararıyla Türkiye'deki eğitim fakültelerinde yer alan öğretmenlik lisans programlarında çeşitli düzenlemeler yapılmıştır (YÖK, 2018). Söz konusu düzenlemelerin BÖTE bölümü müfredatlarında da yansıması görülmüş olup genel kültür, meslek bilgisi ve alan eğitim alanlarında çeşitli derslere yer verilmiştir. Bunlar arasında, birinci sınıf sürecinde eğitimi verilen Öğretim Teknolojilerinin Temelleri (ÖTT) ve Eğitimde Bilgi Teknolojileri (EBT) isimli dersleralan eğitimi kapsamında yer almaktadır. Bunlar arasındaki EBT ders içeriği genel olarak 
incelendiğinde, bilgisayar sistemlerinin yanı sıra ofis uygulamaları, internet ve bilişim etiği konularını kapsamaktadır. Öte yandan ÖTT ders içeriği olarak, eğitim ve öğretim kavramlarının teknoloji ile ilişkisi, öğretim teknolojilerinin tarihsel gelişimi, 21. yüzyıl öğretmen ve öğrenci özellikleri dahilindeeğitim ve teknoloji ilişkisi aktarılarak, bu süreçte rol oynayan temel kavramlar ve bunlara ilişkin çeşitli uygulamalar hakkında bilgilendirmeler yapılmaktadır. Ele alınan ÖTT dersine yönelik, öğretici ve öğrencilere rehber olması noktasında alan uzmanlarıncaulusal nitelikte çeşitli kaynak kitaplar yayınlanmıştır (Çağılttay ve Göktaş, 2018; Kurt, 2018; Şendağ, 2019; Türel, 2019). Söz konusu dersler ile birlikte gerek teorik gerekse uygulamalı olarak yürütülen öğretim faaliyetlerinin,bilgi ve iletişim teknolojisi ile öğretim teknolojisi algısı üzerinde etken olacağı öngörülmektedir. Bu gerekçeyle, BÖTE bölümünde öğrenim görmeye başlayan birinci sınıf öğretmen adaylarının, öğretim teknolojisi kavramına ilişkin zihinlerinde oluşanmetaforik algıların ne şekilde çeşitlendiğinin araştırııması çalışmanın problemini oluşturmaktadır. Araştırmanın amacı, BÖTE bölümünde öğrenim görmeye başlamış birinci sınıf öğrencilerinin ÖTT dersinin başlangıç ve bitiş aşamalarında öğretim teknolojisi kavramına ilişkin algılarının metaforlar aracılı̆ıyla tespiti ve bunlar arasındaki değişim durumunun incelenmesidir. Ders içeriği olarak göz önüne alındığında, öğretim teknolojisi kavramına odaklanan öğretim faaliyetlerine ÖTT dersinde daha yoğun yer verileceği düşüncesiyle, araştırma kapsamındaki uygulamalar bu ders kapsamında gerçekleştirilmiştir. Bu bağlamda aşağıdaki araştırma sorularına yanıt aranmıştır:

- Öğretmen adaylarının öğretim teknolojisi kavramına ilişkin metaforik algıları ÖTT dersi öncesi ne şekildedir?

- Öğretmen adaylarının öğretim teknolojisi kavramına ilişkin metaforik algıları ÖTT dersi sonrası ne şekildedir?

- Öğretmen adaylarının öğretim teknolojisi kavramına ilişkin metaforik algıları ÖTT dersi ve sonrası ne şekilde değişmektedir?

\section{Yöntem}

\section{Araştırmanın Modeli}

Bu çalışmada, öğretmen adaylarının öğretim teknolojisi kavramına ilişkin algılarını ortaya koyabilme adına nitel araştırma yöntemlerinden olgubilim (fenomenoloji) deseninden faydalanılmıştır. Olgu bilim deseniyle yürütülen çalışmalar, bir olguya ilişkin bireysel algıların ayrıntıı bir şekilde ortaya çıkarılmasını ve yorumlanmasını amaçlar (Merriam, 2013, s. 24-25). Bu gerekçeyle, araştırma sürecinde yer alan öğretmen adaylarının öğretim teknolojisi kavramına ait zihinlerinde oluşturmuş oldukları algıların ortaya çıkarılması amaçlandığından, bu desenden faydalanılması uygun görülmüştür.

\section{Çalışma Grubu}

Araştırmanın çalışma grubu, 2018-2019 Güz döneminde BÖTE bölümünde öğrenim gören 18'i erkek 6'sı kadın olmak üzere toplam 24 öğretmen adayından oluşmaktadır. Bu adayların tamamı birinci sınıf öğrencisi olup yaş aralıkları 17-19 arasında değişmektedir. Adayların tamamının,daha önceki senelerde eğitim/öğretim teknolojileriyle ilgili ders almadıkları belirlenmiştir. Çalışma grubunda yer alan katılımcılar,amaçsal örnekleme yöntemlerinden kolay ulaşılabilir durum örnekleme tekniğiyle belirlenmiştir. Bu tekniğin seçilmesindeki gerekçe, uygulama kapsamında yer alması planlanan örneklem grubunun araştırmacının kendisine yakın ve kolay ulaşılabilir özellikte olmasıdır (Yıldırım ve Şimşek, 2013, s. 139). Bu yolla katılımcılar, araştırmacının kendisinin yürütmüş olduğu "Öğretim Teknolojilerinin Temelleri” dersine kayıtlı öğretmen adaylarından oluşmaktadır. Çalışma 
grubunda yer alan adayların araştırma sürecinde gönüllü olarak yer almak istemeleri göz önünde bulundurulmuştur.

\section{Veri Toplama Araçları}

Araştırma sürecinde veri toplama aracı olarak, araştırmacı tarafından hazırlanan form kullanılmıştır. Bu form iki bölümden oluşmakta olup ilk bölümde yaş, cinsiyet ve daha önce öğretim teknolojisi içerikli ders alma durumlarını belirleyen demografik soru grubu yer almaktadır. İkinci bölümde, katılımcıların öğretim teknolojisi hakkındaki algıların belirlemeye yönelik "Öğretim teknolojileri ........ gibidir, çünkü ........" ifadesi yer almakta olup, form üzerindeki boş kısımları tamamlamaları istenmiştir.Form üzerinde yer alan ifadeler virgül (,) işaretiyle ayrılan iki bölümden oluşmaktadır. Bunlardan ilk bölümde metafor yapısı, ikinci bölümde ise bu metaforun dayandığı mantıksal gerekçenin ortaya konulması hedeflenmektedir (Aygün ve diğerleri, 2014, s. 1381). Veri toplama aracının geliştirilmesinde, farklı disiplinler dahilindeki araştırmacıların alanlarına ait kavramsal düşünceleri metaforik olarak ortaya koymayı amaçladıkları çalışmalardan esinlenerek hazırlanmış olup, ilk bölümü oluşturan "Öğretim Teknolojileri" şeklindeki kavramsal ifade araştırmanın amacı doğrultusunda değiştirilmiştir. Form üzerinde boşluklu kısımlarda yazılı olarak belirtilen ifadeler araştırmanın veri kaynağını oluşturmuştur.

\section{Veri Toplama Süreci}

Araştırma kapsamında veri toplama sürecine ait işlemler maddeler halinde aşağıda belirtilmiştir:

1. Araştırma kapsamındaki uygulamalar, 2018-2019 Güz dönemi BÖTE bölümü birinci sınıf alan eğitimi dersleri kapsamında okutulan "Öğretim Teknolojilerinin Temelleri”adlı ders sürecinde yüz-yüze olacak şekildegerçekleştirilmiştir.

2. Veri toplama sürecinde geçilmeden önce araştırmacı tarafından öğrencilere araştırma süreci hakkında bilgilendirmelerde bulunulmuştur. Bu kapsamdametafor kavramı anlatılmış ve ne amaçla kullandığıyla ilgili örnek uygulamalar dahilinde açıklamalar yapılmıştır. Ardından, veri toplama amaçı dağıtılacak formda yer alan boşluklu kısımların tamamlanması hakkında bilgilendirme yapılmıştır.

3. Ders öncesi veri toplama süreci gerçekleştirilme adına, ele alınan dersinin başlangıcında mevcut veri toplama aracı öğrencilere dağıtılmış ve form üzerindeki boşluklu kısımları tamamlamaları istenmiştir.

4. Ilgili derse ait 14 hafta süren ders anlatımları araştırmacı tarafından sınıf ortamında gerçekleştirilmiştir. Bu ders teorik olarak haftada iki saat olacak şekilde işlenmiştir. Ders kapsamında anlatımı planlanan konular, Yüksek Öğretim Kurulu tarafından yürürlüğe konulan bölüm ders içeriklerince belirlenmiştir (YÖK, 2018). Buna göre eğitim ve teknoloji ile ilişkisine ilişkin temel kavramlar, 21. yüzyıl öğretmen ve öğrenci özelliklerindeki değişim ve gereksinimler, öğretim teknolojilerinin dünya ve Türkiye genelindeki tarihi, güncel bilgi ve iletişim teknolojileri dahilinde öğretim alanlarında faydalanılan ortam, araç ve uygulamalar hakkındaki eğitimler ilgili haftalar altında planlanmıştır.

5. İlgili ders anlatımlarının son haftasında aynı veri toplama aracı öğrencilere tekrar uygulanarak ders sonrası veri toplama süreci tamamlanmıştır.

\section{Verilerin Analizi}

Yürütülen uygulamalar neticesinde elde edilen metaforik verilerin çözümlenmesinde içerik analizi yöntemi kullanılmıştır (Merriam, 2013). İçerik analiziyle birlikte, benzer veriler belirli kavram 
ve temalar etrafında bir araya getirilerek okuyucunun anlayabileceği biçimde yorumlama şeklinde gerçekleştirilmektedir (Yıldırım ve Şimşek, 2013, s. 259). Öğretim teknolojisi kavramına ilişkin adaylarca oluşturulan metafor yapıları ile bunlara ait gerekçeler ilişkilendirilmiş ve benzer yapılar dahilinde sınıflandırılmıştır. Bu kapsamda ortaya konan metaforların analizinde: 1. Kodlama ve ayıklama, 2. Derleme, 3. Kategori geliştirme ve 4. Geçerlik-güvenirlik sağlama aşamaları izlenmiştir (Saban, 2008, s. 464). Bu aşamalarda yürütülen işlemler sırasıyla aşağıda açıklanmıştır:

1. Veri toplama amaçlı ders öncesi ve ders sonrası aşamaların her ikisinde de katılımcılarca yazılı olarak tamamlanan formlar sıra numarasına $(1,2,3 \ldots)$ göre sınıflandırılarak adlandırılmıştır.

2. Katılımcılarca üretilen metaforların yapısal özellikleri incelenmiş olup üretilen metaforun kaynağı ve buna ilişkin sunulan mantıksal gerekçeler dikkate alınmıştır. Buna göre, ders öncesi 4 ve ders sonrasında 6 adet olmak üzere mantıksal dayanağı olmayan metafor analiz kapsamı dışında tutulmuştur. Bu durumun nedeni, birinci kısımdaki metafor kaynağının doğru olarak belirtilmesine rağmen ikinci kısımda yer alan ilişkilendirmenin mantıksal dayanağının yüzeysel olması veya boş bırakılmasından kaynaklanmıştır. Ders önce ve ders sonrası aşamalardaki veri toplama süreci öncesi metafor oluşturma amaçlı kaynak ve ilişkilendirme aşamaları hakkında araştırmacı tarafından bilgi verilmesine karşın, bu duruma ilişkinöğrencilerce dikkatli davranılmadığı belirlenmiştir. Analiz dışı bırakılan metafor yapılarına örnek olarak, ders öncesi aşamada "Öğretim teknolojileri bilgisayar gibidir, çünkü bilgisayarda bilmediğimiz bilgileri seyredip program üretebiliriz" ve ders sonrası aşamada "Ögrretim teknolojilerini kalmaktan korktuğum derse benzetirim, çünkü vize sınavı zordu" şeklinde sıralanabilir. Buna göre ders öncesi aşamada 20 ve ders sonrası aşamada 18 metafor değerlendirmeye alınmıştır.

3. Derleme aşamasında, ortaya konan mevcut metafor yapıları ortak özelliklerine göre kodlanarak sınıflandırılmıştır. Buna göre, kabul gören ders öncesi aşamada 20 metafor 5 kategori ve ders sonrası aşamada 18 metafor 4 kategori altında frekans veyüzde gösterimleri şeklinde tablolar halinde sunulmuştur.

4. Metafor yapılarına ait analiz sürecindeki kodlama aşamasında, araştırmacının yanı sıra alan uzmanı bir diğer öğretim elemanı ayrı ayrı görev alış̧tır. Araştırmanın güvenirliğini sağlamak amacıyla yürütülen bu süreçte, kodlama olarak belirlenen metafor yapıları ve bunlara ait kategorilerin karşılaştırması yapılmış, uyumun olmadığı durumlar yeniden değerlendirilerek ortak kanıya ulaşıımıştır. Kodlayıcılar arasındaki tutarııı̆ın sağlanması adına Miles ve Huberman (1994) tarafından geliştirilen güvenirlik formülü (Güvenirlik = Görüş birliği / Görüş birliği +Görüş ayrılı̆̆ X 100) kullanılmıştır. Buna göre, kodlayıcılar arasındaki uyum oranı \%87 olarak tespit edilerek analiz sürecinin güvenirliği sağlanmıştır.

\section{Araştırmacının Rolü}

Nitel desenle yürütülen bu çalışma, yazarca okutulan Öğretim Teknolojinin Temelleri dersi kapsamında sürdürülmüş olup veri toplama sürecinde kendisi görev almıştır.

\section{Araştırmanın Sınırlılıkları}

Araştırma kapsamındaki uygulamalar 2018-2019 eğitim-öğretim yılı güz döneminde gerçekleştirilmiştir. Araştırma sürecinde yer alan çalışma grubu, araştırmacının görev yapmış olduğu üniversitenin eğitim fakültesine ait akademik birimler arasındaki BÖTE bölümünde öğrenim gören birinci sınıf öğretmen adaylarıyla sınırlıdır.Araştırma kapsamındaki uygulamalar Öğretim Teknolojilerinin Temelleri adlı ders kapsamında gerçekleştirilmiştir. Ayrıca araştırma sonuçları,veri toplama aracı kapsamında kullanılan form üzerinde yazılı olarak sunulan bilgilerle sınırıdır. 


\section{Bulgular}

Bu bölümde, elde edilen verilerin araştırmanın alt problemleri bağlamında incelenmesi neticesinde ulaşılan bulgulara yer verilmiştir. Buna göre, ÖTT dersi öncesi ve sonrası aşamalarda öğretim teknolojisi kavramına ilişkinöğretmen adaylarınca ortaya konan metaforlara ait bulgular sınıflandırılarak frekans ve yüzde gösterimleri şeklinde tablolar halinde sunulmuştur. Ardından her iki aşamada belirlenenmetafor yapıları arasında farklılaşma durumu incelenmiştir.

ÖTT dersi öncesi aşamada öğretmen adaylarınca ortaya konulan metafor yapılarına ait bulgular Tablo 1'de verilmiştir.

Tablo 1.

ÖTT dersi öncesi öğretim teknolojisi kavramına ilişkin metaforlara ait betimsel bulgular

\begin{tabular}{|c|c|c|c|c|}
\hline Kategori & Metafor & Metafor sayısı & $f$ & $\%$ \\
\hline $\begin{array}{l}\text { Destekleyici bir yapının } \\
\text { sembolü olarak öğretim } \\
\text { teknolojileri }\end{array}$ & $\begin{array}{l}\text { Mutfak aleti, Kanal, Kural, Uzay, Ebeveyn, } \\
\text { Okyanus, Kitap, Kütüphane, Bina temeli, } \\
\text { Kumbara, Harita, Inşaat }\end{array}$ & 12 & 12 & 60 \\
\hline $\begin{array}{l}\text { Yenilenme sürecinin } \\
\text { sembolü olarak öğretim } \\
\text { teknolojileri }\end{array}$ & İnsan (2), Evren, Hayat & 3 & 4 & 20 \\
\hline $\begin{array}{l}\text { İhtiyacın sembolü olarak } \\
\text { ögretim teknolojileri }\end{array}$ & Kitap, Renk & 2 & 2 & 10 \\
\hline $\begin{array}{l}\text { Kapasitenin sembolü } \\
\text { olarak öğretim } \\
\text { teknolojileri }\end{array}$ & Flash bellek & 1 & 1 & 5 \\
\hline $\begin{array}{l}\text { Sürükleyiciliğin sembolü } \\
\text { olarak öğretim } \\
\text { teknolojileri }\end{array}$ & Gezegen & 1 & 1 & 5 \\
\hline Toplam & & 19 & 20 & 100 \\
\hline
\end{tabular}

Öğretim teknolojisi kavramına ait ders öncesi aşamada ortaya konan metaforlar yapısal özellikleri bağlamında incelendiğinde, 12 öğretmen adayının öğretim teknolojilerini destekleyici bir yapı olarak algıladığı ortaya çıkarılmıştır. Bu kategori altında 12 metafor üretilmiş olup bunlar mutfak aleti, kanal, kural, uzay, ebeveyn, renk, okyanus, kitap, kütüphane, bina temeli, kumbara, harita, inşaat olarak belirtilmiştir. Adaylarca bu kategoride oluşturulan metaforlar, "Öğretim teknolojisi mutfakta kullandığımız aletler gibidir, çünkü mutfakta işimizi kolaylaştıran aletler gibi eğitim hayatını kolaylaştıran elemanlar da öğretim teknolojileridir." (Ö7) ve "Öğretim teknolojisi kural gibidir, çünkü bizim neye ihtiyacımız düşse onla ilişkili kuraldan yararlanarak çözüm üretiriz." (Ö21) şeklinde örneklendirilebilir.

Ders öncesi aşamada öğretim teknolojisine yönelik belirtilen metaforlara ait oluşturulan bir diğer yapısal kategori ise yenilenme süreci olarak belirlenmiştir. Bu kategori altında ortaya konan 3 metaforun 4 öğretmen adayınca üretildiği görülmektedir. Bu metaforlar insan, evren ve hayat şeklindedir. Adaylarca bu kategoride oluşturulan metaforlara örnek olarak "Öğretim teknolojisi insan gibidir, çünkü onu her daim gelişirken görebiliriz." (Ö13) ve "Öğretim teknolojisi hayat gibidir, çünkü teknolojinin gelişmesine bağlı olarak kendini geliştirir." (Ö11) şeklinde verilebilir.

Öte yandan, 2 öğretmen adayınca öğretim teknolojisi kavramı ihtiyacın sembolü olarak algılanmaktadır. Bu kategori altında belirlenen 2 metafor kitap ve renk şeklinde sınıflandırıımıştır. Buna göre kitap metaforunu ortaya koyan Ö3 kodlu adayın “...çünkü aradığım bilgileri onda 
bulabilirim." şeklindeki benzetmesi ile öğretim teknolojilerinin öğrenme sürecini destekleme noktasındaki öneminiortaya koymaktadır. Benzer şekilde öğretim teknolojilerini renk şeklinde algılayan Ö6 bu durumu "... çünkü renksiz hayat olamayacağı gibi öğretim teknolojilerinden yoksun eğitim olamaz." şeklinde gerekçelendirdiği belirlenmiştir.

Tüm bunların yanı sıra, ders öncesi aşamada 1'er öğretmen adayınca öğretim teknolojisine ilişkin belirtilen metafor yapılarının kapasite ve sürükleyicilik kategorileri altında toplandığı görülmektedir. Buna göre, öğretim teknolojisi algısını kapasite metaforu yardımıyla açıklamaya çalışan adayın buna ilişkin benzetmesini “... çünkü öğretim teknolojisi kendisinden daha büyük bilgileri içerisinde barındıır." şeklinde ortaya koymuştur. Son olarak bir diğer öğretmen adayı "... çünküöğretim teknolojisinin ilgi çekici ve buna bağlı merak uyandırıı bir konusu olabilir" şeklindeki açıklamasıyla öğretim teknolojisini gezegene benzetmiş olup, öğretim teknolojilerinde meydana gelen gelişimsel sürükleyici yapının özelliğini ortaya koymaya çalıştığı görülmektedir.

ÖTT dersi sonrası aşamada öğretmen adaylarınca ortaya konulan metafor yapılarına ait bulgular Tablo 2'de verilmiştir.

Tablo 2.

ÖTT dersi sonrası öğretim teknolojisi kavramına ilişkin metaforlara ait betimsel bulgular

\begin{tabular}{|c|c|c|c|c|}
\hline Kategori & Metafor & Metafor sayısı & $f$ & $\%$ \\
\hline $\begin{array}{l}\text { Destekleyici bir } \\
\text { yapının sembolü } \\
\text { olarak öğretim } \\
\text { teknolojileri }\end{array}$ & $\begin{array}{l}\text { Oyuncu, Ok, İletişim, Taş ustası, Gezegen, } \\
\text { Rehber, İnsan beyni, Işık, Doktor, Renk, İletişim, } \\
\text { Makyaj, Kumbara }\end{array}$ & 13 & 13 & 72 \\
\hline $\begin{array}{lr}\text { Yenilenme } & \text { sürecinin } \\
\text { sembolü } & \text { olarak } \\
\text { öğretim teknolojileri }\end{array}$ & Uzay, Renk, Kültür & 3 & 3 & 16 \\
\hline $\begin{array}{l}\text { İhtiyacın sembolü } \\
\text { olarak öğretim } \\
\text { teknolojileri }\end{array}$ & Arkadaş & 1 & 1 & 6 \\
\hline $\begin{array}{lr}\text { Kişisel } & \text { gelişimin } \\
\text { sembolü } & \text { olarak } \\
\text { öğretim } & \text { teknolojileri }\end{array}$ & Doktor & 1 & 1 & 6 \\
\hline Toplam & & 18 & 18 & 100 \\
\hline
\end{tabular}

Öğretim teknolojisi kavramına ait ders sonrası aşamada ortaya konan metaforlar yapısal özellikleri bağlamında incelendiğinde en göze çarpanı, ders öncesi aşamada ortaya çıktığı gibi öğretim teknolojilerinin destekleyici bir yapı olarak algılanmış olduğudur. Bu kategori altında 13 farklı metafor yapısı ortaya çıkarılmıştır. Adaylarca belirtilen metafor yapılarına örnek olarak "Öğretim teknolojisi doktor gibidir, çünkü karşısına gelen hastaya tedavi bulması gibi öğrenmede yaşanacak sorunlara çözüm üretebilir." (Ö8) ve "Öğretim teknolojisi oyuncu gibidir, çünkü bilgiyi bize hem işitsel hem görsel her türlü yolla aktarabilir." (Ö11) verilebilir. Öte yandan Ö3 öğretim teknolojilerini iletişim aracına benzettiği belirlenmiş olup bunun gerekçesini "... çünkü bu araçla internet üzerinden dersler yapılabiliyor. Öğretmen ve öğrenci arasındaki iletişimi rahat bir şekilde yapabildiği için." şeklinde açıklamıştır. Buna göre Ö3 tarafınca öğretim teknolojisi algısı iletişim sürecinin bir öğesi olarak şekillendiği görülmekte olup, öğretmen ve öğrenci arasındaki iletişimi sağlayan kanal rolünü üstlendiği bilincinin kazanıldığı ortaya çıkmaktadır.

Ders sonrası aşamada öğretim teknolojisi algısına ilişkin 3 öğretmen adayınca ortaya konan metaforik ifadelerin gerekçelendirildiği dayanaklar incelendiğinde belirlenen bir diğer kategori ise yenilenme süreci olarak sınıflandırılmıştır. Üç farklı yapıyı kapsayan bu kategoride uzay, renk ve kültür 
şeklinde metaforlar yer almaktadır. Uzaymetaforunu ortaya koyan Ö10 tarafınca belirtilen mantıksal dayanağın "... çünkü sonsuz sayıda bileşeni vardır ve bu bileşen sayısı arttıkça kendini geliştirir." şeklinde açıklaması, öğretim teknolojilerinin farklı ortamlar bazında çeşitlendirilebileceği bilincinin oluştuğunu göstermektedir. Benzer düşüncelerin Ö17'ce ortaya konan“Öğretim teknolojisi insan kültürü gibidir, çünkü teknolojideki gelişmeler onun kültürüne yansıyor." şeklindeki yapıyla desteklendiği belirlenmiş olup söz konusu yenilenme sürecinde teknolojik gelişmelerin etken olduğunu savunulmaktadır.

Öğretim teknolojisini ìhtiyaçkapsamında nitelendiren 1 öğretmen adayı bu durumu "Arkadaş" şeklinde tanımladığı metaforik ifadeyle ortaya koymuştur. Ö13 tarafınca ortaya konan bu algı "Öğretim teknolojisi arkadaşım gibidir, çünkü ihtiyacım olduğunda ona danışır bana yardımcı olur." şeklindeki ifadelerce ortaya çıkarılmıştır. Söz konusu kategori altındaki bu metaforik algı neticesince, öğretimleri sürecinde öğretmenlerceyaşanacağı gibi öğrenmeleri esnasında öğrencilerce de yer verilmesi mümkün bir gereksinimolarak görüldüğü anlaşılmaktadır.

Ders öncesi aşamadan farklı olarak öğretim teknolojisi algısına yönelik ders sonrası aşamada tespit edilen kategori ise "Kişisel gelişim" olarak belirlenmiştir. Ders sonrası aşamada belirlenen destekleyici kategorisinde ortaya çıktığı gibi bu kategori altında da benzer şekilde "doktor" metaforu belirlenmiş olup 1 öğretmen adayınca ortaya konulmuştur. Bir önceki yapıdan farklı olarak Ö9 kodlu aday tarafınca ortaya konan bu metaforda, öğretim teknolojileri alanındaki güncel gelişmelerin takibine bağı olarak bunların derslere ait konu anlatımları sürecinde uygulanması gerekliliğinin vurgulandığı belirlenmiştir. Ö9'ca belirtilen bu durumu adayın “Öğretim teknolojisi bir doktora benzetebiliriz, alanındaki gelişsmeleri takip etmesiyle hem donanım hem de metod açılarından farklıık yaratıp gerekli çözümleri hastalarına sunabilir." şeklindeki ifadeleriyle ortaya çıkarmak mümkündür.

Öğretim teknolojisi kavramına ait metaforik algıdaki farkındalık düzeyini ortaya koyma adına cevap aranan üçüncü alt problemde, ÖTT dersi öncesi ve sonrası aşamalarda belirlenen metafor yapılarındaki değişim durumu karşılaştırılmıştır. Buna göre, ders öncesi ve sonrası aşamalara ortaya konan metaforik kavramlara ilişkin betimsel bulgular farklıı gösterse de bunları kapsayankategorilerin benzer yapılar içerdiği söylenebilir. Bu bulgunun ortaya çıkarılmasında, öğrencilerin yükseköğretim öncesi eğitim kademelerindeki eğitim-öğretim süreçlerinde öğretim teknolojileriyle alakalı yaşanmış deneyimlerin etken olabileceği düşünülmektedir. Ancak, ders öncesi aşamada öğretim teknolojisi kavramı hakkında belirlenen metaforlar daha çok somut materyaller üzerine odaklanırken, metafor yapılarının dayandırıldığı mantıksal gerekçelerdeki ifadelerin ders anlatımlarındaki öğretim sürecine yönelik ağırlık kazanmış olması ders sonrası aşamada daha ön plana çıktığı belirlenmiştir.

\section{Tartışma, Sonuç ve Öneriler}

Bu araştırmada, BÖTE bölümü birinci sınıf öğrencilerinin ÖTT dersinin başlangıç ve bitiş aşamalarında öğretim teknolojisi kavramına yönelik algılarında oluşan metaforik algılarının tespiti ve bunlar arasındaki değişim durumunun analizi neticesinde elde edilen bulgular literatür eşliğinde tartışılarak aşağıdaki sonuçlar elde edilmiştir.

Öğretim teknolojisi kavramına ilişkin adaylarca oluşan algıların, ÖTT dersinin başlangıç ve bitiş aşamalarında farklı metaforlar aracılığıyla açıklanmaya çalışıldığı belirlenmiştir. Buna göre, ders öncesiaşamada 20 öğretmen adayınca 19 farklı metafor tespit edilirken, ders sonrası ise 18 öğretmen adayı 18 metafor üretmiş olup bunlar ortak özelliklerine göre kategorilendirilmiştir. Ders öncesi ve sonrası aşamalarının her ikisinde de öğretmen adaylarınca ortaya konan metaforların hemen hemen yarııında, öğretim teknolojilerinin ders anlatım sürecinde yardımcı etmen özelliğine sahip olma 
fikrinin hakim olduğu göze çarpmaktadır. Toplam sayı olarak bu durum ders öncesinde 12 (\%60) ve ders sonrasında 13 (\%72) metafor şeklinde ortaya konulmuş olup destekleyici bir yapının sembolü olarak sınıflandırılmıştır. Bumetafor yapısı her iki aşamada ortaya çıkarılmasına karşın geçerli metafor sayısı bazında kıyaslandığındaders sonrası aşama lehine daha ön planda olması göz ardı edilmemesi gereken bir durumdur. Ders anlatımları öncesi öğretim teknolojilerinin destekleyici bir unsur olduğu katılımcılarca benimsense de, üniversite eğitimi öncesindeki eğitim-öğretim faaliyetlerince edinilen deneyimlerin bu anlamda etken rol üstlendiği düşünülmektedir. Öğrenme ve öğretme sürecinin niteliğini artırmanın yollarından birinin, öğretim teknolojileri ve bu kapsamda geliştirilen materyaller ile mümkün olabileceği düşüncesi (Lowther ve diğerleri, 2012; Morrison ve diğerleri, 2010), ders sonrası aşama lehine ortaya konan metafor yapılarının altında yatan ortak özellik olarak görülebilir. Öğretim teknolojilerinin, öğretmen ve öğrencilerce dersler kapsamında yer verilmesindeki verimliliği yadsınamaz bir gerçek olup (Kauffman, 2004; Morrison ve diğerleri, 2010; Wong ve Li, 2008), bu durum araştırma kapsamında destekleyici yapı kategorisinde belirlenen metaforlarca ayrıca vurgulandığı belirlenmiştir. Öte yandan araştırmanın sonucunda destekleyici yapı altındakimetaforlar ile farklı araştırmacılarca yürütülen çalışma sonuçlarının (Bas, 2017; Bilgiç, 2021; Durmuş ve Kaya, 2010; Durukan, Hacıoğlu ve Usta Dönmez, 2016; Korkmaz ve Ünsal, 2016; Kuru ve Kuru, 2019; Özer ve Kılıç Türel, 2015; Saraç, 2018; Selçuk, 2018;) benzer özellikler taşıdığıbelirlenmiştir.

Öğretim teknolojisi algısına ilişkin oluşan metaforik yapılarda yoğunluk yaşanan ikinci kategori yenilenme süreci olarak tespit edilmiştir. Bu durum, ders öncesi ve ders sonrası aşamalarda 3'er metafor şeklinde ortaya çıkarılmıştır. Buna göre katılımcılarca, farklılaşan teknolojik gelişmeler bağlamında eğitim-öğretim kademesinde yer alan bireylerin kendini geliştirme ihtiyacı hissetmesinin farkında olunduğunu göstermektedir. Öğretim teknolojisi algısının yenilenme süreci olarak tasvir edilmesi çerçevesinde ortaya konan metaforların yapısal özellikleri incelendiğinde iki farklı durumla karşılaşılmıştır. Bunlardan birincisi, gelişmekte olan teknolojiler bağlamında bireylerin bu teknolojilerden faydalanabilme noktasında kendisinde duyduğu ihtiyaç olarak tanımlanabilir. Nitekim içinde bulunulan zaman diliminde teknoloji alanında yaşanan gelişmelerin eğitim-öğretim faaliyetleri kapsamında yer verilmesi kaçınılmaz olup, söz konusu teknolojilerin deneyimlenmesine yönelik algının öğretmen adaylarınca oluştuğu düşünülmektedir. Bununla birlikte, ders anlatımı sürecindeki etkililiği ve verimliliği sağlama noktasında öğretim teknolojilerinden faydalanma intiyacının hissedilmesi, bu kategori altında ortaya konan metaforik yapıların bir diğer gerekçesi olarak görülmelidir. Özellikle yeni gelişen teknolojiler bağlamında düşünüldüğünde, söz konusu teknolojilerin eğitim ortamına entegrasyonuyla birlikte etkin kullanımı önemli görülmektedir. Bu açıdan değerlendirildiğinde, öğretimin verimliliğini arttırma noktasında öğretim teknolojilerine yer verilmesi gerekliliği göz ardı edilmemesi gereken bir durumdur (Anderson, 2003; Erişti, Kurt ve Dindar, 2012). Bu durum, yürütülen araştırma kapsamındaki öğretim teknolojisi anlayışına yansıdığı görülmekte olup, öğretim esnasında bu teknolojileri yer verilmesi noktasındaki değişime adapte olunması gerekliliği vurgulanmaktadır. Bu kategori altında ortaya çıkan metaforların, Kuru ve Kuru'nun (2019) çalışması sonucu eğitim teknolojisine yönelik ortaya koyduğu reform ve gelişim kategorileri ile Bilgiç (2021) tarafından belirlenen kullanım amaçları altındaki metafor yapıları ile örtüştüğü görülmektedir.

Öğretim teknolojilerinin öğretmen adaylarınca ihtiyacın sembolü olarak algılanması, ders öncesi ve ders sonrası aşamalarda ortak düşünce özelliğine sahip bir diğer kategori olarak karşımıza çıkmaktadır. Oluşan bu kategori ders öncesinde "renk" ve "kitap" ve ders sonrasında ise "arkadaş" metaforları altında sınıflanmıştır. Bu metaforlar, öğretim teknolojisinin intiyaç olarak algılanmasına öncülük eden yapılar olarak betimlenmiştir. Her iki aşamada ortaya konan bu metaforik yapılardan hareketle öğretim teknolojilerinin gerek öğretmenlerce gerçekleştirilecek ders anlatımları, gerekse eğitimleri sürecinde öğrencilerce başvurulması mümkün bir dayanak olarak algılandığı sonucuna varmak mümkündür. Araştırma sonucu ortaya çıkan bu metafor yapısı Kuru ve Kuru (2019)'nun yürütmüş oldukları çalışma kapsamında da ortaya konulmuş olup, eğitim teknolojilerinin temel 
gereksinim kategorisi altında sınıflandırıldığı tespit edilmiştir. Öğretim teknolojileri kapsamında yer verilen akıllı tahta, bilgisayar ve internetin kaçınılmaz olduğunu belirten metaforlara Saraç'ın (2018) çalışmasında da görmek mümkündür.

Ders öncesi ve sonrası aşamalarda ortaya çıkarılan metaforların ortak özellikleri bağlamında oluşturulan kategoriler incelendiğinde, birbirine benzer yapı taşımış olmaları dikkat çekmektedir. Bu benzerlik her iki aşamada ortaya konan destekleyici, yenilenme ve ihtiyaç şeklindeki kategorilerde yaşanmaktadır. Adayların, öğretim teknolojisi kavramı ve özellikleri hakkında üniversite eğitimi kapsamındaki ders anlatımları neticesinde farkındalık kazanmaları beklenirken, benzer kavramsal algıların ders anlatımı öncesindede ortaya belirtilmiş olmasıdikkat çekici bir durum olarak karşımıza çıkmaktadır. Bu durumun en büyük sebebini, araştırma sürecinde yer alan katılımcıların yükseköğretim öncesi öğrenim görmüş olduğu okullarda yaşamış olduğu öğrenim sürecine dayandırmak mümkündür. Milli Eğitim Bakanlığı'na bağlı öğretim kademelerinde görevli öğretmenlerinkitap, föy ve bunların dijital teknolojilerle desteklenmiş versiyonlarışeklinde farklı türden öğretim teknolojilerini ders anlatım sürçlerinde yer vermeleri ve öğrencilerin bunları deneyimlemiş olmaları, öğrencilerin öğretim teknolojisi kavramında bilinçlenmesinin en önemli göstergesi olduğu düşünülmektedir. FATiH projesi ve bu kapsamda sunulan bileşenlerden ortaokul ve lise düzeyindeki eğitim-öğretim faaliyetlerinde faydalanılması, bu bilinçlenmenin altında yatan etkenlerden bir diğeriolarak görülmektedir. FATiH projesi kapsamındaki uygulamaların 2012-2013 eğitim öğretim yılı süreciyle uygulamaya konulmaya başlandığı göz önünde bulundurulursa (MEB, 2012), öğrencilerin öğretim teknolojisi ve bu kapsamda yer verilen öğeler noktasında farkındalık kazanmıs olmaları beklenen bir durum olarak karşımıza çıkmaktadır (Balcı, Gökkaya ve Kar, 2013). Nitekim, araştırmanın yürütüldüğü zaman dilimi ve araştırmada yer alan katılımcıların 17-19 arasında seyreden yaş dağılımları göz önünde bulundurulduğunda adayların okul, kurs veya etüt faaliyetlerinde akıllı tahta, e-kitap, eba, tablet, bilgisayar uygulamalarıyla yüzleşmiş ve bunlardan faydalanmış olmaları muhtemel görülmektedir.

Ders öncesi ve ders sonrası aşamalardaki benzerlikler dışında farkı kategoriler altında farklı metaforik düşüncelerin ortaya konulmuş olması dikkat çekicidir. Ders öncesi aşamada birer öğretmen adayı, öğretim teknolojisi kavramını flash bellek ve gezegen şeklinde metaforik benzetimde bulunmuş ve bunlar sırasıyla kapasite ve sürükleyicilik şeklinde kategorilendirilmiştir. Her iki kategori altında ortaya konan metaforlara ait açıklamalar farklı görüşler neticesinde meydana gelmiş olsa da, diğer yapılardan farklı olarak öğretim teknolojisi kavramını somutlaştırma adına ortaya konulmaya çalışıldığı dikkat çekmektedir. Somutlaştırma durumunun ders öncesi aşamada ortaya çıkması kitap metaforuna ait açıklamalarda da görmek mümkün olup, aranan bilginin bulunduğu ortam olarak tasvir edilmektedir. Bilgiç (2021), kullanım amacı neticesinde belirlediği "Bilgi kaynağı" altındaki metaforlarla bilgiye ulaşılması noktasında eğitim teknolojilerine ait çeşitliliğin önemi ifade edilmiştir. Ortaya konan metaforlara ait benzer özellik Çoklar ve Bağcı (2009) tarafınca da tespit edilmiş olup, yapısal özellik kategorisi altında belirlenen metaforlar ile eğitim teknolojilerinin ortam bazında yer verilen araç olarak görüldüğü ortaya çıkarılmıştır. Ders öncesi aşamadan farklı olarak ders sonrası aşamada öğretim teknolojisiyle ilgili ortaya konan metaforik düşüncelerin, öğretim sürecindeki işlevliğini ön plana çıkaran bir yapı olarak düşünülmesi gerektiğini göstermektedir. Ders sonrası iki farklı kategoride ortaya çıkarılan doktor metaforuna ait açıklamalar bu duruma örnek olarak gösterilebilir. Destekleyici yapı altında ortaya konan bu metafor ile öğrenmede yaşanan sorunlara çözüm üretilebileceği belirtilirken, kişisel gelişim kapsamındaki metafor yapısı ile öğrencilerce güçlük yaşanan kavramsal ifadelerin öğretimi sürecinde öğretim teknolojlerinin kolaylaştırıcı etkisinin vurgulanmaya çalışıldığı anlaşılmaktadır. Araştırma kapsamında elde edilen bu sonuca benzer olarak, Contemporary Issues in Technology and Teacher Education isimli dergi bünyesinde yayınlanmış sosyal bilimlerde eğitim teknolojisi araştırmalarını konu edinen metafor çalışmalarının meta sentezi neticesinde de ortaya konduğu görülmektedir(Mason, 2018).Buna göre, belirlenmiş olan bağlamak ve bağı koparmak şeklindeki metaforik algıları Mekanikleşme kategorisi altında açıklayan Mason, bu 
yapı ile teknolojinin öğrenme ortamlarına entegrasyonu neticesinde öğretme ve öğrenme sürecinde fayda sağlayacağını belirtilmektedir. Benzer şekilde Çoklar ve Bağcı (2009), eğitim teknolojisi kavramına ilişkin öğretmen adaylarında oluşan metafor yapılarını belirleme adına gerçekleştirdiği çalışmada en fazla işlev/rol kategorisi altında metaforlar tespit edilerek, adayların büyük çoğunluğu rolü gereği eğitim teknolojilerini eğitim sürecinin önemli bir bileşeni olarak gördükleri ortaya çıkarılmıştır.

BÖTE bölümünde öğrenim görmeye başlamış birinci sınıf öğrencilerinin, öğretim teknolojisi kavramına ilişkin ders faaliyetlerinin başlangıç ve bitiş aşamalarında söz konusu kavrama ait metaforik algının tespiti ve bunlar arasındaki farklılaşma durumunun ortaya konulması amacıyla yürütülen bu araştırma neticesinde birtakım sonuçlara varılması mümkündür. Araştırma kapsamındaki ortaya konan metaforik yapılardan hareketle, öğretim teknolojilerinin öğretimi destekleyici rolünün betimlenmeye çalışıldığı görülmektedir. Bu metaforların, eğitimleri sürecinde öğretmenlere hitaben ortaya konulmasının yanı sıra öğrencilerce gerçekleşecek öğrenmelere yönelik oluşturulmuş olması dikkat çekicidir. Araştırma kapsamında yer alan katılımcıların yükseköğrenime yeni başlayan öğretmen adaylarınca oluşması dikkate alındığında, Milli Eğitim Bakanlığı'na bağlı okullardaki eğitimöğretim süreçlerinde son yılları kapsayan teknolojik gelişmelerin yer verilme çabasının öğrencilerde farkındalık yarattığı görülmektedir.Öğretim teknolojilerine ilişkin ortaya çıkarılan yapılarla birlikte, öğretimin etkililiği ve verimliliğini sağlama noktasında öğretim teknolojilerinin önemi göz önünde bulundurulmalıdır. Bu bağlamda öğretmen adaylarına, hizmet öncesi eğitimleri sürecinde öğretim teknolojilerinden faydalanabilmeleri noktasında teşvik edici imkanlar sağlanması gerektiği dikkate alınmalıdır. Yürütülen araştırmanın, bilişim teknolojileri öğretmen adaylarının öğretim teknolojisi kavramına ilişkin algılarını ortaya koyma noktasında önemli olduğu düşünülmektedir. Öğretim teknolojisi algısındaki durumu görebilme ve buna uygun öğretimi şekillendirebilme adına, eğitim fakültelerinin farklı bölüm ve programlarda öğrenim gören geniş kitleye sahip öğretmen adayları ile araştırmanın tekrarlanması önerilebilir. 


\section{Kaynakça}

Alkan, C. (2011). Eğitim teknolojisi. Ankara: Anı Yayıncılık.

Alpaydın, Y., Kocabaş, C., Dervişoğulları, M. ve Çakır, G.S. (2019). Öğretmenlik eğitiminde kazandırılan yeterliklerin öğretmenlik mesleği ile uyumu: Öğretmen görüşlerine dayalı bir karma araştırma. Marmara Üniversitesi Atatürk Eğitim Fakültesi Eğitim Bilimleri Dergisi, 49, 17-49.

Anderson, T. (2003). Getting the mix right again: An updated and theoretical rationale for interaction. The International Review of Research in Open and Distance Learning, 4(2). DOI: https://doi.org/10.19173/irrodl.v4i2.149

AECT (Association for Educational Communications and Technology). (2008). Definition. In A. Januszewski \& M. Molenda (Eds.), Educational Technology: A definition with commentary. New York: Lawrence Erlbaum Associates.

Aygün, M., Hacıoğlu, Y. ve Durukan, Ü. G. (2014). Prospective science teachers' metaphorical images about 'Light'. International Conference on Education and Social Sciences, Proceedings of INTCESS14, p.13801388.

Aykaç, N. ve Çelik, Ö. (2014). Öğretmenlerin ve öğretmen adaylarının eğitim programına ilişkin metaforik algılarının karşılaştırılması. Eğitim ve Bilim, 39(173), 328-340.

Balcı, E.Ö., Gökkaya, Z. ve Kar, A. (2013). Fatih projesinin üniversiteler yüzü. İstanbul Sosyal Bilimler Dergisi, 5, 14-30.

Bas, G. (2017). Perceptions of teachers about information and communication technologies (ict): A study of metaphor analysis. Contemporary Educational Technology, 8(4), 319-337

Bilgiç, H. (2021). Aday öğretmenlerin eğitim teknolojileri algısı: Metafor analizi örneği. Eğitim Teknolojisi Kuram ve Uygulama, 11(2) , 211-235.

Can, E. (2019). Öğretmenlerin meslekî gelişimleri: Engeller ve öneriler. Eğitimde Nitel Araştırmalar Dergisi, 7(4), 1618-1650.

Çağıltay, K. ve Göktaş, Y. (2018). Öğretim teknolojilerinin temelleri: Teoriler, araştırmalar, eğilimler (2. Baskı). Ankara: Pegem.

Çivril, H., Aruğaslan, E. ve Özkara-Özaydın B. (2018). Uzaktan eğitim öğrencilerinin uzaktan eğitime yönelik algıları: Bir metafor analizi. Eğitim Teknolojisi Kuram ve Uygulama, 8(1), 39-59.

Çoklar, N.A. ve Bağcı, H. (2009). Öğretmen adaylarının eğitim teknolojisi kavramına yönelik geliştirmiş olduğu metaforlar. Journal of Qafqaz University, 28, 172-184.

Demirel, Ö. (2004). Öğretimde planlama ve değerlendirme, öğretme sanatı. Ankara: Pegem A Yayıncılık.

Durak, H.Y. ve Saritepeci, M. (2017). Investigating the effect of technology use in education on classroom management within the scope of the Fatih project. Çukurova Üniversitesi Eğitim Fakültesi Dergisi, 46(2), 441-457. DOI: 10.14812/cufej.303511

Durukan, Ü.G., Hacıoğlu, Y. ve Usta Dönmez, N. (2016). Bilgisayar ve öğretim teknolojileri öğretmeni adaylarının "Teknoloji" algıları. Bilgisayar ve Eğitim Araştırmaları Dergisi, 4(7), 24-46.

Durmuş, A. ve Kaya, S. (2010). Öğretmen adaylarının öğretim materyali hakkındaki metaforlarının incelenmesi. 4th International Computer and Instructional Technologies Symposium (ICITS 2010), (pp. 452-456).

Erden, M. (2005). Öğretmenlik mesleğine giriş. İstanbul: Epsilon Yayınları.

Erişti Bedir, S.D., Kurt, A.A. ve Dindar, M. (2012). Teachers' views about effective use of technology in classrooms. Turkish Online Journal of Qualitative Inquiry, 3(2), 30-41.

Ertmer, P. A. (2005). Teacher pedagogical beliefs: The final frontier in our quest for technology integration? Educational Technology Research and Development, 53, 25-39

Farisi, M. I. (2016). Developing the 21st-century social studies skills through technology integration. Turkish Online Journal of Distance Education, 17(2), 16-30.

Fidan, M. (2014). Öğretmen adaylarının teknoloji ve sosyal ağ kavramlarına ilişkin metaforik algıları. The Journal of Academic Social Science Studies, 25(1), 483-496.

Gedik, N. (2017). Examining the conceptualization of instructional technology in Turkey. Contemporary Educational Technology, 8(1), 76-98. 
Haggis, T. (2004). Constructions of learning in higher education: Metaphor, epistemology, and complexity. In J. Satterthwaite \& E. Atkinson (Eds.), The disciplining of education: New languages of power and resistance (pp. 181-197). Stoke on Trent: Trentham.

Harris, J. L., Al-Bataineh, M. ve Al-Bataineh, A. (2016). One to one technology and its effect on student academic achievement and motivation. Contemporary Educational Technology, 7(4), 368-381

Haşlaman, T., Kuşkaya-Mumcu, F. ve Usluel, Y. K. (2007). The integration of information and communication technologies in learning and teaching process: A lesson plan example. Education and Science, 32(146), 54-63.

Hew, K. F. ve Brush, T. (2007). Integrating technology into K-12 teaching and learning: Current knowledge gaps and recommendations for future research. Educational Technology Research and Development, 55(3), 223-252.

Hsu, S. ve Kuan, P.-Y. (2013). The impact of multilevel factors on technology integration: The case of Taiwanese grade 1-9 teachers and schools. Educational Technology Research and Development, 61(1), 25-50.

Jensen, D. F. N. (2006). Metaphors as a bridge to understanding educational and social contexts. International Journal of Qualitative Methods, 5(1), 36-54.

Kabakçı Yurdakul, I. (2011). Öğretmen adaylarının teknopedagojik eğitim yeterliklerinin bilgi ve iletişim teknolojilerini kullanımları açısından incelenmesi. Hacettepe Üniversitesi Eğitim Fakültesi Dergisi, 40, 397-408.

Karataş, K. (2020). Öğretmenlik mesleğine kuramsal bir bakış. Elektronik Eğitim Bilimleri Dergisi, 9(17), 39-56.

Kauffman, D. F. (2004). Self-regulated learning in web-based environments: Instructional tools designed to facilitate cognitive strategy use, metacognitive processing, and motivational beliefs. Journal of Educational Computing Research, 30, 139-161.

Kaya, G. ve Usluel, Y. K. (2011). Öğrenme-öğretme süreçlerinde bit entegrasyonunu etkileyen faktörlere yönelik içerik analizi. Buca Eğitim Fakültesi Dergisi, 31, 48-67.

Kıyıcı, G. ve Yumuşak, A. (2005). Fen bilgisi laboratuarı dersinde bilgisayar destekli etkinliklerin öğrenci kazanımları üzerine etkisi. The Turkish Online Journal of Educational Technology, 4, 130-134.

Koç, M. (2013). Student teachers' conceptions of technology: A metaphor analysis. Computers and Education, 68, 1-8.

Korkmaz, F. ve Ünsal, S. (2016). Okul öncesi öğretmenlerin “teknoloji” kavramına ilişkin metaforik algılarının incelemesi. Mustafa Kemal Üniversitesi Sosyal Bilimler Enstitüsü Dergisi, 13(35), 194-212.

Kuru, E.,ve Kuru, O. (2019). Sınıf öğretmeni adaylarının eğitim teknolojisi kavramına ilişkin metaforik algıları. Kahramanmaraş Sütçü Imam Üniversitesi Sosyal Bilimler Dergisi, 16(1), 257-278.

Kurt, A. A. (2018). Öğretim teknolojilerinin temelleri. Nobel Yayın Dağıtım: Ankara.

Lakoff, G. ve Johnson, M. (2007). Metaforlar: Hayat, Anlam ve Dil (Çev. Demir, G.Y.). İstanbul: İthaki Yayınları.

Lei, J. ve Zhao, Y. (2008). One-to-one computing: What does it bring to schools? Journal of Educational Computing Research, 39(2):97-122. doi:10.2190/EC.39.2.a

Lowther, D. L., Inan, F. A., Ross, S. M. ve Strahl, J. D. (2012). Do one-to-one initiatives bridge the way to 21st century knowledge and skills? Journal of Educational Computing Research, 46(1), 1-30.

Mason, L. (2018). A critical metaphor analysis of educational technology research in the socials tudies. Contemporary Issues in Technology and Teache Education, 18(3), 538-555.

Mazman, S. G. ve Usluel, Y.K. (2011). ICT integration in the learning-teaching process: Indicators and models. Educational Technology Theory and Practice, 1(1), 62-80.

Merriam, S. B. (2013). Nitel araştırma desen ve uygulama için bir rehber (Çev. Turan, S.). Ankara: Nobel Yayıncılık.

Milli Eğitim Bakanlığı (MEB) (2012). Eğitimde FATiH Projesi web sayfası. Alınan yer http://fatihprojesi.meb.gov.tr/index.html

Miles, M, B. ve Huberman, A. M. (1994). Qualitative data analysis: An expanded sourcebook. (2nd ed). Thousand Oaks, CA: Sage.

Morrison, G. R., Ross, S. M., Kemp, J. E. ve Kalman, H. (2010). Designing effective instruction: Applications of instructional design (6th. Ed.), New York, NY: Wiley.

Odabaşı, H. F. (2007). Öğretim teknolojileri ve materyal geliştirme. Eskişehir: Anadolu Üniversitesi. 
Özdemir, M. A. (2015). Eğitim teknolojilerinin fen ve teknoloji derslerinde kullanılması: Bir durum çalışması. Journal of Educational Studies, 3(4), 137-148.

Özer, S. ve Türel Kılıç, Y. (2015). Bilişim teknolojileri öğretmen adaylarının e-kitap ve etkileşimli e-kitap kavramına ilişkin metaforik algıları. Turkish Online Journal of Qualitative Inquiry, 6(2), 1-23.

Perkmen, S. ve Tezci, E. (2011). Eğitimde teknoloji entegrasyonu: Materyal geliştirme ve çoklu ortam tasarımı. Ankara: Pegem Akademi.

Reigeluth, C. ve Joseph, R. (2002). Beyond technology Integration: The case for technology transformation. Educational Technology, 42, 9-12.

Reiser, R. A. (2012). What field did you say you were in? Defining and naming our field. InR. A. Reiser, \& J. V. Dempsey (Eds.), Trends and issues in instructional design and technology (3rd ed.) (pp. 1-7). Boston MA: Pearson Education.

Saban, A. (2008). Okula ilişkin metaforlar. Kuram ve Uygulamada Eğitim Yönetimi, 55, 459-496.

Sarac, H. (2018). Use of instructional Technologies by teachers in the educational process: Metaphor analysis study. European Journal of Educational Research, 7(2), 189-202.

Selçuk, G. (2018). Türkçe öğretmen adaylarının öğretim teknolojileri ve materyal tasarımı dersine ilişkin metaforik algılarının incelenmesi. Akdeniz Eğitim Araştırmaları Dergisi, 12(26), 526-543.

Sezgin, F., Erdoğan, O., ve Erdoğan, B. H. (2017). Öğretmenlerin teknoloji öz yeterlikleri: Öğretmen ve öğrenci görüşlerine yönelik bütüncül bir analiz. Eğitim Teknolojisi Kuram ve Uygulama, 7(1), 180-199.

Şahin, ş. ve Baturay, M. H. (2013). Ortaöğretim öğrencilerinin internet kavramına ilişkin algılarının değerlendirilmesi: Bir metafor analizi çalışması. Kastamonu Eğitim Dergisi, 21(1), 177-192.

Şahin İzmirli, Ö. ve Köse, E. (2018). Öğretmen, öğrenci ve okul yöneticilerine göre sınıfta teknolojinin rolleri: Teknolojiyi sınıfta kim, neden istiyor? Eğitimde Nitel Araştırmalar Dergisi, 6(3), 246-266

Şendağ, S. (2019). Öğretim teknolojileri etkili ve eğlenceli öğrenme deneyimi tasarım rehberi. Nobel Yayın Dağıtım: Ankara.

Şimşek, N. (2007). Öğretim teknolojileri kullanımı ve materyal geliştirme (Uygulama örnekleriyle). Ankara: Asil.

Tosuntaş, Ş.B., Emirtekin E. ve Süral i., (2019). Eğitim ve öğretim teknolojileri konusunda yapılan tezlerin incelenmesi (2013-2018). Yükseköğretim ve Bilim Dergisi, 9(2), 277-286.

Türel, Y. K. (2019). Öğretim teknolojileri. Asos Yayınları.

Wang, Q. ve Woo, H. L. (2007). Systematic planning for ict integration in topic learning. Educational Technology and Society, 10(1), 148-156.

Wong, E. M. L. ve Li, S. C. (2008). Framing ict implementation in a context of educational change: A multilevel analysis. School Effectiveness and School Improvement,19(1), 99-120.

Yıldııım, A. ve Şimşek, H. (2013). Sosyal bilimlerde nitel araştırma yöntemleri. (9. Baskı). Ankara: Seçkin Yayıncilık.

Yılmaz, G. K. ve Güven, B. (2015). Öğretmen adaylarının uzaktan eğitime yönelik algılarının metaforlar yoluyla belirlenmesi. Turkish Journal of Computer and Mathematics Education, 6(2), 299-322.

Yob, I. M. (2003). Thinking constructively with metaphors. Studies in Philosophy and Education, 22, 127-138.

YÖK (Yükseköğretim Kurulu). (2018). Yeni öğretmen yetiştirme lisans programları (programların güncelleme gerekçeleri, getirdiği yenilikler ve uygulama esasları). https://www.yok.gov.tr/kurumsal/idaribirimler/egitim-ogretim-dairesi/yeni-ogretmen-yetistirme-lisans-programlari adresinden erişilmiştir. 